

Received/Geliş: 15.05.2019

\section{Turkish Stuties Educational Sciences}

Volume 14 Issue 4, 2019, p. 1353-1366 DOI: 10.29228/TurkishStudies.23313 ISSN: 2667-5609

Skopje/MACEDONIA-Ankara/TURKEY

Research Article / Araştırma Makalesi

Article Info/Makale Bilgisi

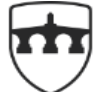

INTERNATIONAL BALKAN UNIVERSITY

EXCELLENCE FOR THE FUTURE IBU.EDU.MK

Gor Report Dates/Rapor Tarihleri: Referee 1 (05.06.2019)-Referee 2 (25.07.2019)

This article was checked by iThenticate.

\title{
16-17 YAŞ GRUBU ÖĞRENCİLERDE DAİRESEL ANTRENMAN PROGRAMININ DENGE VE MOTOR ÖZELLIKLERE ETKISİ
}

\author{
Canan Gülbin ESKIYYECEK - Betül BAYAZIT** \\ Hakan TAN $N^{* * *}$ - Cemre Can AKKAYA****
}

\begin{abstract}
ÖZ
$\mathrm{Bu}$ araştırmanın amac1, 16-17 yaş grubu spor lisesi öğrencilerine uygulanan 8 haftalık denge yoğunluklu dairesel egzersizlerin öğrencilerin motorsal özellikleri (esneklik, sıçrama kuvveti, sırt kuvveti) ve denge performansları üzerine etkisinin incelenmesidir. Araştırma grubunu, Hayrettin Gürsoy Spor Lisesi'nde öğrenim gören 28 gönüllü erkek öğrenci oluşturmuş ve öğrenciler deney grubu (n:14; yaş: $16 \pm 0$ y1l; boy uzunluğu: $169.75 \pm 6.53 \mathrm{~cm}$; vücut ağırlığ1: $60.31 \pm 9.4 \mathrm{~kg}$ ) ve kontrol grubu (n:14; yass: $16.79 \pm 0.43$ yll; boy uzunluğu: $168.93 \pm 4.29$ $\mathrm{cm}$; vücut ağırlı̆̆ı: $61.59 \pm 4.98 \mathrm{~kg}$ ) olmak üzere iki gruba ayrılmıștır. Araştırmada flamingo denge, otur eriş uzan esneklik, dikey sıçrama ve sirt kuvveti testleri ön test ve son test şeklinde uygulanmıştır. Antrenmana katılan öğrencilere haftada 2 gün ve günde 1 saat olmak üzere toplam 8 hafta denge yoğunluklu (statik ve dinamik denge) dairesel antrenmanlar uygulanmıştır. Araştırmada elde edilen verilerin analizinde SPSS 24.0 istatistik paket programindan faydalanılarak, tanımlayıcı istatistikler ile birlikte ön test ve son test değerlerinin karşılaştırmasında grup içi ölçüm sonuçları Wilcoxon testi, gruplararası ölçüm sonuçları ise Mann-Whitney U testi ile hesaplanmıștır. Anlamlılık düzeyi ise $\mathrm{p}<0.05$ olarak belirlenmiştir. Araştırmada, deney grubunun ön test ve son testleri arasında; esneklik, dikey sıçrama, sırt kuvveti, flamingo denge testi sağ ve sol değerlerinde, kontrol grubunun ön test
\end{abstract}

\section{Dr. Öğr. Üyesi, Mardin Artuklu Üniversitesi, E-posta: cgulbineskiyecek@gmail.com}

Doç. Dr. Kocaeli Üniversitesi, E-posta: betul.bayazit@kocaeli.edu.tr

Yüksek Lisans Öğencisi, Kocaeli Üniversitesi, E-posta: hakantan798@ hotmail.com

Yüksek Lisans Öğencisi, Kocaeli Üniversitesi, E-posta: cancemre1@gmail.com 
ve son testleri arasında; vücut ağırlığı, esneklik, sırt kuvveti ve BKİ değerlerinde, gruplar arası ön test ve son testleri arasında ise flamingo denge testi sağ ayak son testinde istatistiksel olarak anlamlı farkll11klar bulunmuştur $(\mathrm{p}<0.05)$. Bunun nedeni, uygulanan çalışma program içeriğinin çocukların gelişim seviyesine uygun olmasına ve çalışmaya odaklanarak daha iyi bir gelişim ortaya koymalarına bağlanabilir.

Anahtar Kelimeler: Dairesel Antrenman, Dairesel Denge Antrenman1, Motor Özellik

\title{
THE EFFECTS OF CIRCULAR TRAINING PROGRAMME ON BALANCE AND MOTOR PROPERTIES IN 16-17 AGE GROUP STUDENTS
}

\begin{abstract}
The aim of this study was to investigate the effects of 8 -week equilibrium-density circular exercises in 16-14 age sport high school students motor characteristics (flexibility, bounce strength, back force) and balance performance. The study group consisted of 28 volunteer male students studying at Hayrettin Gursoy Sports High School and students divided into two groups; experimental group (n: 14; age: $16 \pm 0$ years; height: $169.75 \pm 6.53 \mathrm{~cm}$; body weight: $60.31 \pm 9.4 \mathrm{~kg}$ ) and control group (n:14; age: $16.79 \pm 0.43$ years; height: $168.93 \pm 4.29 \mathrm{~cm}$; body weight: $61.59 \pm 4.98 \mathrm{~kg})$. In this study, flamingo balance, seated flexibility, vertical jump and back strength tests were applied as pre-test and post-test. Circular exercises (dynamic and static balance) were applied to students participating in the training for 2 weeks and 1 hour in 2 days per week. In the analysis of the data obtained from the study by using SPSS 24.0 statistics package program, together with the descriptive statistics the results of the intra-group in the comparison of pre-test and post-test values were calculated Wilcoxon tests, between groups were calculated with the Mann-Whitney U test. The level of significance was determined as $\mathrm{p}<0.05$. In the research, the flexibility between the pre-test and post-test of the experimental group, vertical jump, back force, flamingo balance test right and left values, pre-test and post-test between the control group, body weight, flexibility, back force and BMI values were noticed. statistically significant differences were found between the pre-test and post-test flamingo balance test right foot post-test $(p<0.05)$. This can be attributed to the fact that the content of the study program is appropriate to the child's level of development and focuses on working better.
\end{abstract}

\section{STRUCTURED ABSTRACT}

\section{Introduction}

In an effective training program for children and adolescents, the psycho-physical characteristics of each age range should be taken into account to maximize and focus on age-related motor learning abilities (Ricotti, 2011). Weineck (2001) defined the basic age ranges by determining the sensitivity of each age in learning a specific motor skill 
for children and young people. Therefore, in order to create good athletes, the importance given to the complete and harmonic development of motor abilities at an early age is of paramount importance at all stages of the athlete's body development, first of all with regard to age-specific ones (Ricotti, 2011).

The balance performance is an important factor especially in many branches in terms of the development of the motor skills of sports high school students. Human ability to achieve balance can be defined as a determining factor in the development of other motor systems (Aksu, 1994). It is emphasized that balance performance evaluations are important in terms of sports performance and long-term balance trainings increase performance. In addition, since balance exercises are associated with neuromuscular control during movement, it is recommended that balance and neuromuscular training should be used as an important preparatory program in all stages of long-term athlete development and especially in the early stages (Atess et al., 2017).

The circular training method is programmed according to the motor ability to be developed and it is expected that the maximum efficiency will be obtained from the selected training method (Yamaner and Turgut, 2017). Starting from here; Circular training is a timeeffective training method where predetermined work-rest rates and a group of exercises are performed in a specific order. These exercises can be both anaerobic (strength training) and a combination of strength training and aerobic training (Lundin, 1993).

\section{Purpose of Study}

The aim of this study, which was made considering the effect of circular training on balance performance and motor characteristics, investigated to determine the effect of 8-week balance intensity station exercises on motor characteristics (flexibility, jump strength, back strength) and balance performances of 16-17 age group sports high school students.

\section{Material and Method}

The population of the study was composed of 14 experimental groups (16-17 years old) who were randomly selected for the purpose of the study. The study group was selected from the students of Hayrettin Gursoy Sports High School in 2018-2019 a total of 28 volunteer male students, whose are $16 \pm 0$ years; height: $169.75 \pm 6.53 \mathrm{~cm}$; body weight: $60.31 \pm 9.4 \mathrm{~kg}$ ) and 14 control groups (age: $16.79 \pm 0.43$ years; height: $168.93 \pm 4.29 \mathrm{~cm}$; body weight: $61.59 \pm 4.98 \mathrm{~kg}$ ).

Ethics committee approval was received from Kocaeli University Non-Interventional Clinical Research Ethics Committee (KU GOKAEK) with the number 2018/322 and project number 12.12.2018 in order to conduct the study. Subjects were given information about the subject of research and has been signed voluntary participation form from all subjects and their parents.

For research "Equilibrium Density Circuit Training Exercises Work Plan" was prepared and the experimental group at week 2 days and 1 hours a day (10 min warm up, 40 min from the main section and 10 min cooling) the density balance for a total of 8 weeks, including (static and dynamic balance) circuit training, were applied. The control

Turkish Studies - Educational Sciences

Volume 14 Issue 4, 2019 
group did not receive any training program. In addition, the experimental and control groups participated in the study continued their sports high school courses within their own programs.

In this study, the height, body weight and autoretic characteristics of the subjects were measured in Hayrettin Gursoy Sports High School sports hall. The Flamingo Balance Test, Sit-and-Go Flexibility Test, Vertical Jump Strength Test and Back Strength Test measurements of balance intensity circular training exercises were applied to the students in the experimental and control groups as pretest and post-test. Before measurements, subjects were asked to warm up and stretch for 15 minutes. During the warm-up, subjects were subjected to 5 minute paced running and 10 minute dynamic and static movements.

In analyzing the data obtained in this study utilizing the SPSS 24.0 software package programme, Wilcoxon test for intergroup comparison with descriptive statistics, and in intergroup comparison Mann-Whitney U test was used. Significance level was accepted as $\mathrm{p}<0.05$.

\section{Findings}

In the study, when the pre-test and post-test averages of the experimental group were compared; flexibility $(Z=-3.297)$, vertical jump $(Z=-3.187)$ and back power $(Z=-2.731)$, flamingo right balance test $(Z$ $=-2.697)$ and left $(Z=-2.507)$ values that were statistically significant differences $(\mathrm{p}<0.05)$.

When the pre-test and post-test averages of the control group were compared; body weight $(Z=-2.271)$, flexibility $(Z=-2.518)$, back force $(Z=-2.233)$ and BMI $(Z=-2.202)$ were found to be statistically significant differences $(\mathrm{p}<0.05)$.

When the mean and post-test averages of the experimental and control groups were compared; flamingos right leg balance test $(Z=-$ 2.538) in the last test was found to be statistically significant differences $(\mathrm{p}<0.05)$.

\section{Discussion and Results}

In an effective training program for children and young people, the psycho-physical characteristics of each age range should be taken into account to maximize and focus on age-related motor learning abilities. Therefore, in order to create good athletes, athlete's body at every stage of development with regard to the age-specific first and foremost, the motor skills at an early age the importance of a complete and harmonic development is of primarly importance (Ricotti, 2011).

In addition to the fact that the movements such as sudden pushing, pulling and falling down from the motor skills are the majority in the course content of sports high school students, the balance is important in many branches, and the balance performance in different branches has become an important factor in the sports high school students.

Based on this; Circular training is a time-effective training method where predetermined work-rest rates and a group of these exercises can 
be both anaerobic and a combination of strength training and aerobic training (Lundin, 1993).

The results of 8 week balance intensity circular exercises on the motor characteristics (flexibility, jump strength, back strength) and balance performances of 16-17 year-old sports high school students were discussed in the context of the study and compared with other studies in the literature.

According to the findings of the research; there were significant improvements in flexibility, vertical jump, back strength, flamingo balance test, right foot and left foot values between the pre and post tests of the experimental group $(\mathrm{p}<0.05)$. There was a significant improvement in body weight, flexibility, back strength and BMI between the pre and post tests of the control group $(\mathrm{p}<0.05)$. Significant changes were observed in the right foot post-test among the pre-test and posttest flamingo balance test between the groups $(\mathrm{p}<0.05)$.

In the literature, there are many studies examining the relationship of circular exercises with balance performances and motoric properties. In addition, very few authors have focused on possible strategies for children's balance development and concluded that different sports activities are effective on postural strategies at an early age (Ricotti, 2011).

As a result, it can be said that the content of the circular training program applied with balance intensity is appropriate to the level of development of the children and that they can develop better by focusing on the study.

Keywords: Circular Training, Circular Balance Training, Motor Parameters

\section{Giriş}

Çocuklar ve gençler için etkili bir antrenman programında, yaşa bağlı motor öğrenme yeteneklerinden maksimum seviyede faydalanmak ve odaklanmak için her yaş aralığının psiko-fiziksel özellikleri dikkate alınmalıdır (Ricotti, 2011). Weineck (2001), çocuklar ve gençler için belirli bir motor becerinin öğrenilmesinde, her yaşın duyarlılığını belirleyerek temel yaş aralıklarını tanımlamıştır. Dolayısıyla, iyi sporcular yaratmak için, sporcunun vücut gelişiminin her aşamasında, her şeyden önce yaşa özgü olanlarla ilgili olarak, erken yaşlarda motor yeteneklerin eksiksiz ve harmonik gelişimine verilen önem birincil öneme sahiptir (Ricotti, 2011).

Spor lisesi öğrencilerinin motor becerilerinin gelişimi açısından özellikle birçok branşta denge performansı önemli bir faktördür. Denge, iyi bir performans için temel oluşturmakta ve kas, sinir sistemi içinde iletici olarak tanımlanmaktadır. İnsanın denge sağlamadaki yeteneği, diğer motor sistemlerin gelişmesinde belirleyici bir faktör olarak tanımlanabilir (Aksu, 1994). Denge statik ve dinamik olmak üzere ikiye ayrılmaktadır. Postüral denge veya statik denge, minimum hareketle bir destek temelini sürdürme yeteneği olup "belli bir yerde ya da pozisyonda sağlama yeteneği”, dinamik denge ise sabit bir pozisyonu korurken bir görevi yerine getirme yeteneği olup "vücudun bütünü ya da bir kısmının dengesini sağlama yeteneği” olarak tanımlanabilir (Winter, 1990; Kuşakoğlu, 2012).

Denge hem gövde hem de bacaktaki otomatik postüral (duruş) ve gönüllü motor komutlarının etkileşimini içermektedir (Behm vd, 2004). Denge performans değerlendirmelerinin sportif performans açısından önemli olduğu ve uzun süre yapılan denge antrenmanlarının performansı 
artırdığg vurgulanmaktadır. Ayrıca denge egzersizleri hareket sırasında nöromüsküler kontrol ile ilişkili olduğundan dolayı denge ve nöromüsküler antrenmanların uzun süreli sporcu gelişiminin tüm safhalarında ve özellikle erken dönemlerde önemli bir hazırlık programı olarak kullanılması gerektiği tavsiye edilmektedir (Ateş vd, 2017).

Dairesel antrenman yöntemi geliştirilmek istenen motor yeteneğe göre programlanır ve bu program düzenlenirken seçilen antrenman yönteminden en fazla verimin alınması beklenir (Yamaner ve Turgut, 2017). Buradan yola çıkarak; dairesel antrenman, önceden belirlenmiş çalışma-dinlenme oranları ile bir grup egzersizin belirli bir sırayla gerçekleştirildiği, zaman açısından etkin bir antrenman yöntemidir. Bu egzersizler hem anaerobik (kuvvet antrenmanı) hem de kuvvet antrenmanı ve aerobik antrenmanının bir kombinasyonu olabilir (Lundin, 1993).

Dairesel antrenmanların denge performansı ve motor özellikleri üzerine etkisinin önemi göz önüne alınarak yapılan bu çalışmanın amacı, 8 haftalık denge yoğunluklu istasyon çalışmaları uygulamalarının, 16-17 yaş grubu spor lisesi öğrencilerinin motorsal özelliklerine (esneklik, sıçrama kuvveti, sırt kuvveti) ve denge performanslarına etkisini araştırmaktır.

\section{Materyal ve Metod}

\section{Araştırmanın Evren ve Örneklemi}

Araştırma evrenini, 2018-2019 eğitim öğretim y1lında Hayrettin Gürsoy Spor Lisesi'nde öğrenim gören öğrenciler, örneklem grubunu ise herhangi bir rahatsılı̆ğı (fiziksel ve mental) bulunmayan ve araştırmanın amacına yönelik olarak rastgele yöntem ile seçilmiş 16-17 yaş aralığındaki 14'ü deney ve 14'ü kontrol grubu olmak üzere toplam 28 gönüllü erkek öğrenci oluşturmuştur.

\section{Veri Toplama Yöntemi}

Araştırmanın yürütülebilmesi için Kocaeli Üniversitesi Girişimsel Olmayan Klinik Araştırmalar Etik Kurulu'ndan (KÜ GOKAEK) 2018/322 sayılı ve proje numarası 12.12.2018 ile etik kurul onayı alınmıştır. Deneklere araştırmanın konusu ile ilgili bilgiler verilmiş ve tüm denek ve velilerden imzalı gönüllü katılım formu alınmıştır.

Denge yoğunluklu dairesel antrenmanlar, Hayrettin Gürsoy Spor Lisesi spor salonunda gerçekleştirilmiştir. Araştırma için "Denge Yoğunluklu Dairesel Antrenman Alıştırmaları Çalışma Planı" hazırlanmış ve deney grubuna özel denge yoğunluklu dairesel alıştırmalar 8 hafta boyunca ve haftada 2 gün 1'er saatlik programlar şeklinde uygulanmıştır. Kontrol grubuna ise herhangi bir antrenman programı uygulanmamıştır. Ayrıca araştırmaya katılan deney ve kontrol grupları kendi programları dâhilinde spor lisesi derslerine devam etmiştir. Araştırmada grupların normal antrenmanları Beden Eğitimi Öğretmenleri ile birlikte gerçekleştirilmiş, özel denge yoğunluklu dairesel antrenmanlar ise araştırmacılar tarafindan uygulanmıştır.

\section{Veri Toplama Araçları}

Araştırmada deneklerin boy uzunluğu (mezura ile cm cinsinden), vücut ağırlığı (elektronik tart1 ile kg cinsinden) ile birlikte motorik özelliklerin ölçümü Hayrettin Gürsoy Spor Lisesi spor salonunda gerçekleştirilmiştir. Denge yoğunluklu dairesel antrenman alıştırmalarının ölçümleri deney ve kontrol grubunda yer alan öğrencilere ön test ve son test şeklinde uygulanmış ve ölçümlere geçilmeden önce deneklerin $15 \mathrm{dk}$. süre ile 1 sınma ve germe yapmaları istenmiştir. Isınmada deneklere, 5 dakikalık hafif tempolu düz koşu ile 10 dakikalık dinamik ve statik hareketleri içeren germe hareketleri yaptırılmıştır. 


\section{Beden Kitle İndeksi (BKI)}

Beden Kitle İndeksi ölçümleri;

$$
B K \dot{\mathrm{I}}=\frac{V \ddot{\mathrm{u}} \mathrm{cut} A \breve{\mathrm{g}} \mathrm{lrl} l \mathrm{~g} \mathrm{l}(\mathrm{kg})}{B o y\left(m^{2}\right)}
$$

formülü kullanılarak hesaplanmıştır.

\section{Flamingo Denge Testi}

Araştırmada deneklerin statik dengelerini ölçmek amaciyla Flamingo Denge Testi kullanılmıştır. Test protokolüne uygun olarak deneklerin; $50 \mathrm{~cm}$ uzunluğunda, $4 \mathrm{~cm}$ yüksekliğinde ve $3 \mathrm{~cm}$ genişliğinde tahta bir denge aletinin üzerine hem dominant hem de dominant olmayan ayağ ile çıkarak $1 \mathrm{dk}$ boyunca dengede durmaları istenmiştir. Denekler diğer bacağını geriye bükerek, aynı tarafta bulunan eli ile tutup Flamingo gibi durmaya çalışmışlardır. Serbest kalan kol ise dengeyi sağlamak için kullanılmıştır. Test her denge kaybedildiğinde durdurulmuş, denek denge aletine çıkarak dengesini tekrar sağladığında ise süre kaldığı yerden devam etmiştir. Süre tamamlandığında, deneklerin her denge sağlaması (düştükten sonra) sayılmış ve test bitiminde her bir sporcuya ait sayılar test puanı olarak kaydedilmiştir (Adam vd, 1988).

\section{Otur Eriş Esneklik Testi}

Deneklerin bel ve hamstring kaslarının esnekliğini ölçmek amacıyla yapılan esneklik testi Tek park marka Sit\&Reach Box ile cm cinsinden ölçülmüştür. Ölçüm sırasında deneklerin çıplak ayak tabanlarını sehpanın iç yüzeyine dayayarak dizlerini bükmeden oturma pozisyonuna geçtikten sonra elleri vücudun önünde olacak şekilde sehpanın önündeki cetveli mümkün olabildiği kadar en uzağa itmesi istenmiştir. Test 2 kez tekrarlanmış ve en yüksek değer kaydedilmiştir.

\section{Dikey Sıçrama Kuvveti Testi}

Dikey sıçrama kuvveti Takai marka T.K.K. 5406 JUMP-MD cihazı ile cm cinsinden ölçülmüştür. Deneklerden "mat"ın üzerinde dik duruş pozisyonundayken, çift ayakla dizlerden aşağıya doğru çömelip hız alarak maksimum kuvvetleriyle yukarıya sıçramaları istenmiştir. Test 2 kere tekrar edilmiş ve en iyi derece kayıt altına alınmıştır.

\section{Sirt Kuvveti Testi}

Sırt kuvveti ölçümleri Takai Marka T.K.K. 5102 sırt kuvveti dinamometresi ile kg cinsinden ölçülmüş̧ür. Deneklerden dizleri bükük durumda dinamometre sehpasının üzerine ayaklarını yerleştirdikten sonra, sırt düz, kollar gergin ve gövde hafifçe öne eğikken, elleri ile kavradığ dinamometre barını dikey olarak maksimum oranda sırt kaslarını kullanarak yukarı çekmeleri istenmiştir (Aslan vd, 2011). Bu test 2 kez tekrarlanmış ve en iyi değer kaydedilmiştir.

\section{Denge Yoğunluklu Dairesel Antrenman Prosedürü}

Araştırmada uygulanan antrenman programı; 8 hafta boyunca, haftada 2 gün ve günde 1 saat olmak üzere $10 \mathrm{dk}$ isınma, $40 \mathrm{dk}$ ana bölüm ve $10 \mathrm{dk}$ soğuma şeklinde denge geliştirici, sıçrama geliştirici ve sırt kuvveti geliştirici çalışmalardan oluşturulmuştur. Uygulanan antrenmanlarda huni, sağlık topu, çember, slalom çubukları ve yer minderi ekipmanları kullanılmıştır. Ayrıca dairesel antrenman içeriğinde, vücut ağırlığıyla yapılan hareketler de uygulanmıştır. Çalışma süresi $30 \mathrm{sn}$ yüklenme 30 sn dinlenme şeklinde ve 1:1 yüklenme-dinlenme oranı ile gerçekleştirilmiştir. 2. ay antrenman süresi $45 \mathrm{dk}$ olarak ayarlanmış, şiddet ve hareket zorluk seviyeleri arttırılıp benzer hareketlerden oluşan daha dinamik bir antrenman programı uygulanmıştır. 


\section{Uygulanan Antrenman Programı:}

8 haftalık denge yoğunluklu dairesel antrenman programı haftalara ve günlere göre dizayn edilmiş ve öğrencilere uygulanmıştır.

Antrenmanin Uygulama Süresi: 8 Hafta

Haftalık Antrenman Sayısı: 2

Toplam Antrenman Saylsi: 16

Metod: Dairesel antrenman metodu

Alıştırma Temposu: Akıcı tempo ile

Antrenmanın Şiddeti: Giderek artan direnç doğrultusunda çalışıldığı için \% 40'tan başlayıp zaman içinde \% 55 seviyesine çıkarılmıştır.

Antrenmanin Kapsamı: 10 tekrar her seride

Isinma süresi: $10 \mathrm{dk}$ dinamik 1 sinma

Uygulama Süresi $40 \mathrm{dk}$

Dinleme Saylsi: 1:1 dinlenme

Set Sayısı: 3 set

Set Arası Dinlenme: $3 \mathrm{dk}$ setler arası dinlenme

Soğuma: $10 \mathrm{dk}$ soğuma

huni.

Kullanılan Araç ve Gereçler: Slalom, atlama çubukları, yer minderi, sağlık topu, çember ve

Denge yoğunluklu circuit (dairesel) antrenmanların şiddeti başlangıçta \%40 olup, sonraki haftalarda öğrencilerin gelişim seviyelerine göre $\% 40-\% 45-\% 50$ ve $\% 55$ 'e kadar çıkarılmıştır. Uygulanan alıştırmaların organizasyonu seriler şeklinde gerçekleştirilmiştir. Yüklenme orta-yüksek (amaca göre), akıcı bir tempo ile 30-45 sn süreli 3 seri olarak uygulanmıştır.

\section{Alıştırmalar:}

1.Hafta: Çift bacak çömel-sıçra, tek ayak öne ve geri sıralı çapraz sıçra, sağlık topunu yukarı at-sıçra, mekik bacaklara uzanarak sağ sol, öne adım al çömel ve üst gövde dış rotasyonu, tek bacak denge bacağı geri uzat doğrul, çift bacak sıçra ve tek bacak düş, bank duruşu çapraz el ayak kaldır.

2.hafta: Sıçrayarak el ayak koordineli aç kapat, durarak tek bacak sıçrama, sağlık top ile öne uzanıp doğrulma, V şeklinde mekik, tek bacak önde çömelme, yana sıçrayarak dengede kal, tek bacak öne ve arkaya denge, açık bacak plank.

3.hafta: Sağlık topu baş üstünde çömelme, şınav pozisyonunda çapraz el-ayak kaldırma, çift bacak sıçrama, sağlık topu ensede üst gövdeyi geriye kaldırma, ağırlık topu ile parmak ucu yükselme, dik duruşta tek bacak $90^{\circ}$ kaldırma, çift bacak parmak ucu sıçrama, tek bacak çömelme.

4.hafta: Sağlık topu baş üstünde çömelme, tek ayak sağ sol sıçrama, çift bacak öne sıçra dön geri sıçra, sağlık topu ile öne düz gövde eğil doğrul, bank pozisyonunda çapraz el ve ayak kaldır bekle, parmak ucu çift ayak sıçra, tek bacak dengede diğer bacak yana aç kapa, plank duruşu.

5.hafta: Parmak ucu çift ayak sıçra, sağlık topu ile öne düz gövde eğil doğrul, $50 \mathrm{~cm}$ engelin üzerinden çift ayak sıçrama, plank duruşu, mekik bacaklara uzanarak sağ sol, tek ayak olduğu yerde bacağı göğse çekme, $20 \mathrm{~cm}$ engelden tek ayak yan atlama, dik duruşta tek bacak $90^{\circ}$ yukarı kaldırma.

6.hafta: Çift ayak sıçra bacakları göğse çek, sağlık topu ile öne düz gövde eğil doğrul,50 cm engelin üzerinden çift ayak sıçrama, plank duruşu, mekik bacaklara uzanarak sağ sol, tek ayak olduğu yerde bacağı göğse çekme, $20 \mathrm{~cm}$ engelden tek ayak yan atlama, dik duruşta tek bacak $90^{\circ}$ yukarı kaldırma.

7.hafta: Çift ayak sıçra bacakları göğse çek, sağlık topu ile öne düz gövde eğil doğrul,50 cm engelin üzerinden çift ayak sıçrama, plank duruşu, sağlık topu ile mekik bacaklara uzanarak sağ sol, 
tek ayak parmak uçlarında olduğu yerde sıçrama, $20 \mathrm{~cm}$ engelden tek ayak yan atlama, dik duruşta tek bacak yukar $190^{\circ}$ kaldırma.

8.hafta: Çift ayak sıçra bacakları göğse çek tek ayak düş, sağlık topu ile parmak ucunda sıçrama,50 cm engelin üzerinden çift ayak sıçrama, bank pozisyonunda çapraz el ve ayak kaldır bekle, sağlık topu ile mekik bacaklara uzanarak sağ sol, tek ayak parmak uçlarında olduğu yerde sıçrama, 20 $\mathrm{cm}$ engelden tek ayak yan atlama, dik duruşta tek bacak $90^{\circ}$ yukarı kaldırma.

\section{Verilerin İstatistiksel Analizi}

Araştırmada öğrencilerin değişkenleri üzerinde yapılan ölçümlerde bulunan sonuçlar arasında istatistiki açıdan önemli bir fark olup olmadığını belirlemek amacıyla; ön test ve son test değerlerinin tanımlayıcı istatistikleri ile birlikte grup içi karşılaş̧ırmalarda Wilcoxon testi, gruplar arası karşılaştırmalarda ise Mann-Whitney U testi kullanılmıştır. Verilerin analizinde SPSS 24.0 istatistik paket programından faydalanılmış ve anlamlılık düzeyi $\mathrm{p}<0.05$ olarak kabul edilmiştir.

\section{Bulgular}

Bu bölümde araştırma sonucunda elde edilen bulgular, aşağıda tablolar halinde sunulmuştur.

Tablo 1: Deney grubunun ön test ve son test değerlerinin karşılaştırılması (Wilcoxon testi)

\begin{tabular}{|c|c|c|c|c|c|}
\hline \multirow{2}{*}{ Değişkenler } & \multirow[b]{2}{*}{$\mathbf{N}$} & Ön Test & Son Test & \multirow{2}{*}{$\mathbf{Z}$} & \multirow{2}{*}{$\mathbf{p}$} \\
\hline & & $\bar{X} \pm S S$ & $\bar{X} \pm \mathbf{S S}$ & & \\
\hline Boy Uzunluğu (cm) & 14 & $169.75 \pm 6.53$ & $169.75 \pm 6.53$ & .000 & 1.000 \\
\hline Vücut A ̆ğırlığı (kg) & 14 & $60.31 \pm 9.4$ & $60.55 \pm 9.7$ & -.314 & .753 \\
\hline Esneklik (cm) & 14 & $17.78 \pm 5.01$ & $19.59 \pm 5.46$ & -3.297 & $.001 *$ \\
\hline Dikey Sıçrama (cm) & 14 & $44.71 \pm 7.96$ & $49.79 \pm 6.51$ & -3.187 & $.001 *$ \\
\hline Sirt Kuvveti (kg) & 14 & $114.71 \pm 29.61$ & $136.11 \pm 38.7$ & -2.731 & $.006 *$ \\
\hline $\begin{array}{c}\text { Flamingo Denge (Sağ } \\
\text { Ayak) }\end{array}$ & 14 & $3.14 \pm 3.28$ & $1.00 \pm 1.11$ & -2.697 & $.007 *$ \\
\hline $\begin{array}{c}\text { Flamingo Denge (Sol } \\
\text { Ayak) }\end{array}$ & 14 & $2.5 \pm 2.59$ & $1.5 \pm 1.65$ & -2.507 & $.012 *$ \\
\hline BKİ $\left(\mathbf{k g} / \mathbf{m}^{2}\right)$ & 14 & $20.86 \pm 2.56$ & $20.94 \pm 2.57$ & -.408 & .683 \\
\hline
\end{tabular}

$*=p<0.05$

Tablo 1'e göre, deney grubunun ön test ve son test ortalamaları karşılaştırıldığında; esneklik, dikey sıçrama, sırt kuvveti, flamingo denge testi sağ ve sol değerlerinde istatistiksel olarak anlamlı farklılıklar olduğu tespit edilmiştir $(\mathrm{p}<0.05)$. Diğer parametrelerde ise istatistiksel açıdan anlamlı bir fark tespit edilmemiştir ( $\mathrm{p}>0.05)$.

Tablo 2: Kontrol ön test ve son test değerlerinin karşılaştırılması (Wilcoxon testi)

\begin{tabular}{|c|c|c|c|c|c|}
\hline \multirow[b]{2}{*}{ Değişkenler } & & Ön Test & Son Test & \multirow{2}{*}{$\mathbf{Z}$} & \multirow[b]{2}{*}{$\mathbf{p}$} \\
\hline & & $\overline{\mathrm{X}} \pm \mathrm{SS}$ & $\overline{\mathrm{X}} \pm \mathrm{SS}$ & & \\
\hline Boy Uzunluğu (cm) & 14 & $168.93 \pm 4.29$ & $168.93 \pm 4.29$ & .000 & 1.000 \\
\hline Vücut Ăğırlığı (kg) & 14 & $61.59 \pm 4.98$ & $62.64 \pm 5.08$ & -2.271 & $.023 *$ \\
\hline Esneklik (cm) & 14 & $21.30 \pm 5.63$ & $21.82 \pm 5.08$ & -2.518 & $.012 *$ \\
\hline Dikey Sıçrama (cm) & 14 & $47.07 \pm 7.01$ & $46.71 \pm 6.01$ & -1.058 & .290 \\
\hline Sirt Kuvveti (kg) & 14 & $117.25 \pm 23.75$ & $119.82 \pm 24.27$ & -2.233 & $.026 *$ \\
\hline Flamingo Denge (Sağ Ayak) & 14 & $2.29 \pm 2.33$ & $2.5 \pm 1.74$ & -.711 & .477 \\
\hline Flamingo Denge (Sol Ayak) & 14 & $1.93 \pm 2.23$ & $2.57 \pm 2.43$ & -1.728 & .084 \\
\hline BKİ $\left(\mathrm{kg} / \mathrm{m}^{2}\right)$ & 14 & $21.59 \pm 1.7$ & $21.97 \pm 1.82$ & -2.202 & $.028 *$ \\
\hline
\end{tabular}


Tablo 2'ye göre, kontrol grubunun ön test ve son test ortalamaları karşılaş̧ırıldığında; vücut ağırlığı, esneklik, sırt kuvveti ve BKİ değerlerinde istatistiksel olarak anlamlı farklılıklar olduğu tespit edilmiştir $(\mathrm{p}<0.05)$. Diğer parametrelerde ise istatistiksel açıdan anlamlı bir fark tespit edilmemiştir $(\mathrm{p}>0.05)$.

Tablo 3: Gruplararası ön test ve son test değerlerinin karşılaştırılması (Mann-Whitney U testi)

\begin{tabular}{|c|c|c|c|c|c|c|}
\hline \multirow{2}{*}{ Değişkenler } & \multirow{2}{*}{$\mathbf{N}$} & \multirow{2}{*}{ Ölçümler } & Deney Grubu & Kontrol Grubu & \multirow{2}{*}{$\mathbf{Z}$} & \multirow{2}{*}{$\mathbf{p}$} \\
\hline & & & $\bar{X} \pm S S$ & $\overline{\mathrm{X}} \pm \mathbf{S S}$ & & \\
\hline \multirow[b]{2}{*}{ Boy Uzunluğu (cm) } & \multirow[b]{2}{*}{14} & Ön Test & $169.75 \pm 6.53$ & $168.93 \pm 4.29$ &,- 207 & ,836 \\
\hline & & Son Test & $169.75 \pm 6.53$ & $168.93 \pm 4.29$ & -.207 & .836 \\
\hline \multirow[b]{2}{*}{ Vücut Ağırlığı (kg) } & \multirow[b]{2}{*}{14} & Ön Test & $60.31 \pm 9.4$ & $61.59 \pm 4.98$ & -.138 & .809 \\
\hline & & Son Test & $60.55 \pm 9.7$ & $62.64 \pm 5.08$ & -.689 & .491 \\
\hline \multirow[b]{2}{*}{ Esneklik (cm) } & \multirow[b]{2}{*}{14} & Ön Test & $17.78 \pm 5.01$ & $21.30 \pm 5.63$ & -1.678 & .093 \\
\hline & & Son Test & $19.59 \pm 5.46$ & $21.82 \pm 5.08$ & -1.058 & .290 \\
\hline \multirow[b]{2}{*}{ Dikey Sıçrama (cm) } & \multirow[b]{2}{*}{14} & Ön Test & $44.71 \pm 7.96$ & $47.07 \pm 7.01$ & -.903 & .366 \\
\hline & & Son Test & $49.79 \pm 6.51$ & $46.71 \pm 6.01$ & -1.568 & .117 \\
\hline \multirow[b]{2}{*}{ Sirt Kuvveti (kg) } & \multirow[b]{2}{*}{14} & Ön Test & $114.71 \pm 29.61$ & $117.25 \pm 23.75$ & -.184 & .854 \\
\hline & & Son Test & $136.11 \pm 38.7$ & $119.82 \pm 24.27$ & -1.287 & .198 \\
\hline \multirow{2}{*}{$\begin{array}{c}\text { Flamingo Denge (Sağ } \\
\text { Ayak) }\end{array}$} & \multirow[b]{2}{*}{14} & Ön Test & $3.14 \pm 3.28$ & $2.29 \pm 2.33$ & -.467 & .641 \\
\hline & & Son Test & $1.00 \pm 1.11$ & $2.5 \pm 1.74$ & -2.538 & $.011^{*}$ \\
\hline \multirow{2}{*}{$\begin{array}{c}\text { Flamingo Denge (Sol } \\
\text { Ayak) }\end{array}$} & \multirow[b]{2}{*}{14} & Ön Test & $2.5 \pm 2.59$ & $1.93 \pm 2.23$ & -.798 & .425 \\
\hline & & Son Test & $1.5 \pm 1.65$ & $2.57 \pm 2.43$ & -1.359 & .174 \\
\hline \multirow{2}{*}{ BKİ $\left(\mathbf{k g} / \mathbf{m}^{2}\right)$} & \multirow[b]{2}{*}{14} & Ön Test & $20.86 \pm 2.56$ & $21.59 \pm 1.7$ & -.781 & .435 \\
\hline & & Son Test & $20.94 \pm 2.57$ & $21.97 \pm 1.82$ & -1.034 & .301 \\
\hline
\end{tabular}

$*=\mathrm{p}<0.05$

Tablo 3'e göre, deney ve kontrol grubunun öne test ve son test ortalamalar1 karşılaştırıldığında; flamingo denge testi sağ ayak son testinde istatistiksel olarak anlamlı farklılıklar olduğu tespit edilmiştir $(p<0.05)$. Diğer parametrelerde ise istatistiksel açıdan anlamlı bir fark tespit edilmemiştir ( $p>0.05)$.

\section{Tartışma ve Sonuç}

Bu bölümde, 8 haftalık denge yoğunluklu dairesel egzersizlerin 16-17 yaş arası spor lisesi öğrencilerinin motorsal özellikleri (esneklik, sıçrama kuvveti, sırt kuvveti) ve denge performansları üzerindeki etkisine ilişkin elde edilen sonuçlar, araştırmanın içeriği çerçevesinde tartışılmış ve literatürdeki diğer çalışmalar ile karşılaştırılmıştır.

Araştırma sonucunda elde edilen bulgulara göre; deney grubunun ön test ve son testleri arasında esneklik, dikey sıçrama, sırt kuvveti, flamingo denge testi sağ ayak ve sol ayak değerlerinde anlamlı iyileşmeler olduğu gözlenmiştir $(\mathrm{p}<0.05)$. Kontrol grubunun ön test ve son testleri arasında vücut ağırlı̆̆ı, esneklik, sırt kuvveti ve BKİ değerlerinde anlamlı iyileşme gözlenmiştir $(p<0,05)$. Gruplar arası ön test ve son testleri arasında ise flamingo denge testi sağ ayak son testinde anlamlı değişmeler olduğu gözlenmiştir $(\mathrm{p}<0.05)$. 
Literatüre bakıldığında, dairesel egzersizlerinin denge performansları ve motorik özellikleri ile olan ilişkisini inceleyen çok sayıda çalışmaya rastlanmaktadır. Ayrıca, çok az sayıda yazar, çocukların denge gelişimleri için olası stratejiler üzerinde yoğunlaşmış ve farklı spor aktivitelerinin erken yaşlarda postürel stratejiler üzerinde etkili olduğu sonucuna varmıştır (Ricotti, 2011). Behm vd. (2004) alt ekstremiteye uygulanan statik denge egzersizlerinin propriyosepsiyon, reaksiyon ve hareket süresine etkisinin belirlenmesi amacıyla yaptığ 1 çalışmada, hem bireysel hem de takım sporlarında dengedeki düşük ancak önemli değişikliklerin önemli sonuçlara neden olacağ

Güler ve Eniseler (2017) genç futbolculara uygulanan altı haftalık futbola özgü denge antrenmanlarının çabukluk ve dikey sıçrama performansları üzerine etkilerini belirlemek amacıyla yaptıkları çalışmada, statik ve dinamik denge antrenmanlarının futbolcuların çabukluk ve güç performansını geliştirdiğini saptamışlardır. Ayrıca, denge antrenmanlarının futbol antrenmanlarında destekleyici bir antrenman olarak kullanılmasının da önemli olduğu ifade edilmiştir.

Avelar ve ark. (2016) veteran kadın sporcularda denge egzersizlerinin kas gücü, denge ve fonksiyonel performansının ne düzeyde iyileştirebileceğinin araştırıldığı çalışmada, kadınlarda gelişmiş kas kuvvet ve gücü, denge gelişimi ve fonksiyonel kapasiteye yol açtığı ifade edilmiştir. Ayrıca çalışmada günlük düzenli yaşam aktivitesinin yaşlılar için büyük önem taşıdığına vurgu yapılmıştır.

Ateş ve Ateşoğlu (2014) 16-18 yaş grubu erkek futbolculara uygulanan pliometrik antrenmanların alt ve üst ekstremite kuvvet parametreleri üzerine etkisini araştırdıkları çalışmada, esneklik artışı sağladığını ve farklı yöntemlerle yapılan kuvvet çalışmalarının esneklik performansı üzerine olumlu etkileri olduğunu gösteren çalışmalar bulunduğunu aktarmışlardır. Ayrıca gruplar arasında ortaya çıkan dikey sıçrama değerlerindeki anlamlı artışın, yapılan pliometrik egzersizlerin sıçrama kuvvetini geliştirmesinden kaynaklandığını bildirmişlerdir.

Avery vd. (1996) 7-12 yaş grubu erkek ve kız çocukları üzerinde yaptıkları çalışmada, 8 haftalık kuvvet antrenmanlarının ve ardından 8 haftalık antrenmansız kalma periyodunun değerlendirildiği çalışmada, kuvvet antrenmanlarının dikey sıçrama ve esneklik değerini etkilemediğini ve çocukların antrenmansız kaldıkları dönemde kuvvet kaybettiklerini saptamışlardır.

Bavlı (2009) 12 haftalık pliometrik antrenmanların adölesan basketbolcular üzerine etkisini araştırdığı çalışmada, basketbolcuların dikey sıçrama performanslarının ön test ve son test puanları arasında istatistiksel açıdan anlamlı farklılıklar bulmuştur $(\mathrm{p}<0.05)$.

Ürer ve Kılınç (2014) 15-17 yaş aralığındaki hentbol oyuncularında direnç antrenmanlarına ek olarak yapılan pliometrik egzersizlerin hentbolcuların dikey sıçrama performanslarında anlamlı düzeyde gelişme sağladığını vurgulamışlardır $(\mathrm{p}<0.05)$. Literatür ile benzer şekilde spor lisesi öğrencilerinin dikey sıçrama değerlerinin ön test ve son test ölçümleri arasında anlamlı farklılık olduğu ortaya çıkmıştır $(\mathrm{p}<0.05)$.

Cerrah vd. (2016) 14 yaş grubu erkek futbolcular üzerinde uygulanan fonksiyonel denge antrenmanlarının, futbolcuların statik-dinamik denge performanslarını olumlu şekilde iyileştirdiği belirtilmişsir.

Bağcı (2016) 8 hafta uygulanan kuvvet antrenmanlarının 12-14 yaş arası güreşçi çocukların bazı fiziksel parametreleri üzerine etkilerini incelemiş, deney hem de kontrol grubunun grup içi ve gruplar arasındaki BMI değerlerinde istatiksel olarak anlamlı bir değişim olmadığını belirtmiştir $(\mathrm{p}>0.05)$.

İri vd. (2018) 12-15 yaş arası güreşçi çocuklara uygulanan 8 haftalık denge antrenmanlarının statik-dinamik denge, çeviklik ve sürat performansları üzerine etkisini inceledikleri çalışmada, uygulanan denge egzersizlerinin güreşçi çocukların statik-dinamik denge yeteneklerini olumlu yönde geliştirdiği bildirilmiştir $(\mathrm{p}<0.05)$. 
Doğan vd. (2016) tarafından 18-30 yaş aralığındaki futbolculara uygulanan 8 haftalık core antrenmanın bazı fiziksel ve fizyolojik parametrelere etkisinin araştırıldığ çalışmada, deney grubunun tüm parametrelerinin, kontrol grubunun BKİ, vücut ağırlı̆̆ı, dikey sıçrama, esneklik ve sırt kuvveti değerlerinin, gruplar arası karşılaştırmalarda ise BKİ, esneklik ve sırt kuvveti değerlerinin ön test ve son test ölçümleri arasında anlamlı değişmeler gözlendiği bildirilmiştir $(\mathrm{p}<0.05)$. Literatürden farklı olarak bu araştırmada, gruplar arası BKİ, esneklik ve sırt kuvveti değerlerinin ön test ve son test ölçümleri arasında anlamlı değişmeler gözlenememiştir $(p<0.05)$. Ortaya çıkan bu farkın; uygulama gruplarının yaş aralıklarından ve kullanılan antrenman metodunun farklı olmasından dolayı olduğu düşünülmektedir.

Yüksel vd. (2016) 18 yaş ve üzeri basketbolcularda core antrenmanların denge üzerindeki etkilerini inceledikleri çalışmada, deney grubunun denge yeteneğinin hem sağ ayakta hem de sol ayakta kontrol grubuna kıyasla gelişim gösterdiğini bildirmişlerdir. Literatür ile benzer şekilde 8 haftalık denge yoğunluklu egzersizlerin deney grubu ön test ve son test değerleri arasında ve gruplar arası karşılaştırmalarda flamingo denge testinin hem sağ ayak hem de sol ayak üzerinde olumlu şekilde gelişmeler olduğu gözlenmiştir.

McLeod vd. (2009) 6 haftalık denge antrenmanlarının bayan basketbolcuların denge gelişimleri üzerindeki etkisini incelemek amacıyla yaptıkları çalışmada, yıldız denge testinin ön test ve son test ölçümleri arasında anlamlı sonuçlar bulduklarını bildirmişlerdir $(\mathrm{p}<0.05)$.

Sonuç olarak, denge yoğunluklu olarak uygulanan dairesel antrenman programı içeriğinin, çocukların gelişim seviyesine uygun olduğu ve çalışmaya odaklanarak bu sayede daha iyi bir gelişim gösterdikleri söylenebilir.

\section{KAYNAKÇA}

Afyon, Y. A. ve Boyac1, A. (2016). 18 Yaş Grubu Futbolcularda 8 Haftalik Merkez Bölge (Core) Antrenmanlarının Bazı Motorik Özelliklerin Gelişimine Etkisi. Journal of Human Sciences, 13(3), 4595. doi.org/10.14687/jhs.v13i3.3924

Adam, C. V., Klissouras, M., Ravazollo, R., Renson, W. and Tuxworth, ley, California: MIG Communications. W. (1988). EUROFIT: European Test of Physical Fitness. Handbook. Rome, Italy. Council of Europe, Committee for the Development of Sport. Committee of Experts on Sports Research, 10-70.

Aksu, S. (1994). Denge Eğitiminin Etkilerinin Postüral Stres Testi ile Değerlendirilmesi. Bilim Uzmanlığı Tezi, Hacettepe Üniversitesi Sağlık Bilimleri Enstitüsü, Ankara.

Aslan, C. S., Büyükdere, C., Köklü, Y., Özkan, A. \& Özdemir, N. Ş. (2011). Elit altı sporcularda vücut kompozisyonu, anaerobik performans ve sırt kuvveti arasındaki ilişkinin belirlenmesi. Uluslararası İnsan Bilimleri Dergisi, 8(1), 1612-1628.

Ateş, M. ve Ateşoğlu, U. (2014). Pliometrik Antrenmanin 16-18 Yaş Grubu Erkek Futbolcularin Üst ve Alt Ekstremite Kuvvet Parametreleri Üzerine Etkisi. SPORMETRE Beden Eğitimi ve Spor Bilimleri Dergisi, (1), 21-28.

Ateş, B., Çetin, E. \& Yarım, İ. (2017). Kadın Sporcularda Denge Yeteneği ve Denge Antrenmanları. Gaziantep Üniversitesi Spor Bilimleri Dergisi, 2(2).

Avelar, B. P., Costa, J. N. de A., Safons, M. P., Dutra, M. T., Bottaro, M., Gobbi, S. \& Lima, R. M (2016). Balance Exercises Circuit improves muscle strength, balance, and functional performance in older women. Journal of the American Aging Association, 38(1), 14. doi.org/10.1007/s11357-016-9872-7 
Avery, D. F., Wayne L. W., Lyle J. M., A, R. O., Cindy J. L., Rita LaRosa, L. \& Leanordo D. Z. (1996). The Effects of Strength Training and Detraining on Children. The Journal of Strength and Conditioning Research, 10(2), 109-114. doi.org/10.1519/1533-4287(1996)010

Bağcı, O. (2016). 12-14 Yaş Arası Güreşçilerde 8 Haftalık Kuvvet Antrenmanının Bazı Fiziksel Uygunluk Parametrelerine Etkisi. Yüksek Lisans Tezi, Selçuk Üniversitesi Sağlık Bilimleri Enstitüsü, Konya.

Bavl1, Ö. (2019). Havuz Pliometrik Egzersizleri İle Alan Pliometrik Egzersizlerinin Adolesan Dönem Basketbolcuların Biyomotorik ve Yapısal Özelliklerine Etkisi. Yayımlanmamış Doktora Tezi, Çukurova Üniversitesi, Sağlık Bilimleri Enstitüsü, Adana.

Behm, D. G., Bambury, A., Cahill, F. \& Power, K. (2004). Effect of acute static stretching on force, balance, reaction time, and movement time. Medicine and Science in Sports and Exercise, 36(8), 1397-1402. doi: 10.1249/01.MSS.0000135788.23012.5F

Cerrah, A. O., Bayram, İ., Yıldızer, G., Uğurlu, O., Şimşek, D. \& Ertan, H. (2016). Effects of functional balance training on static and dynamic balance performance of adolescent soccer players. International Journal of Sports, Exercise and Training Science, 2(2), 73-81.

Güler, Ö. ve Eniseler, N. (2017). Genç Futbolcularda Futbola Özgü Denge Antrenmanlarinin Çabukluk ve Dikey Siçrama Performansına Etkileri. Niğde Üniversitesi Beden Egitimi ve Spor Bilimleri Dergisi, 11(3), 259-267.

İri, R., Engin, H. \& Aktuğ, Z. B. (2018). 12-15 Yaş Arası Güreşçilerde 8 Haftalık Denge Antrenmanının Denge Çeviklik ve Sürat Performansı Üzerine Etkisi. Gaziantep Üniversitesi Spor Bilimleri Dergisi, 3(1), 81-90.

Kuşakoğlu, Ö. (2012). Adölesan Dönemde Farklı Yaş Gruplarındaki Erkek Futbolcularda Çevikliğin Değerlendirilmesi. Fizyoterapi ve Rehabilitasyon Yüksek Lisans Programı, İstanbul Bilim Üniversitesi, İstanbul.

Lundin, C.B (1993). Circuit Training Exercise Apparatus.

McLeod, T. C. V., Armstrong, T., Miller, M., \& Sauers, J. L. (2009). Balance improvements in female high school basketball players after a 6 week neuromuscular-training program. Journal of Sport Rehabilitation, 18, 465-481.

Doğan, G., Mendeş, B., Akcan, F. \& Tepe, A. (2016). Futbolculara Uygulanan Sekiz Haftalık Core Antrenmanın Bazı Fiziksel ve Fizyolojik Parametreler Üzerine Etkisi. Niğde Üniversitesi Beden Eğitimi ve Spor Bilimleri Dergisi, 10(1), 1-12.

Ricotti, L. (2011). Static and dynamic balance in young athletes. Journal Human Sport Exercise, 6(4), 616- 628. doi: 10.4100/jhse.2011.64.05

Ürer, S. ve K1lınç, F. (2014). 15-17 Yaş Grubu Erkek Hentbolculara Üst ve Alt Ekstremiteye Yönelik Uygulanan Pliometrik Antrenmanların Dikey Sıçrama Performansına ve Blok Üstü Şut Atış1 İsabetlilik Oranına Etkisinin Araştırılması. Beden Eğitimi ve Spor Bilimleri Dergisi, 1(2), 16381.

Weineck, J. (2001). Optimales Training. Verlag, Gmbh.

Winter, D. A., Patla, A. E. \& Frank, J. S. (1990). Assessment of balance control in humans. Medical Progress through Technology, 16, 31-51.

Yamaner, F. ve Turgut, A. (2017). Dairesel Antrenman Sirasında Uygulanan Farklı Dinlenme Sürelerinin Kan Laktat Düzeyine ve Kalp Atım Hızına Etkisinin İncelenmesi. Uluslararası Balkan Spor Bilimleri Kongresi, 21-23 May1s, 16. 
Yüksel, O., Akkoyunlu, Y., Karavelioğlu, M. B., Harmancı, H., Kayhan, M. \& Koç, H. (2016). Basketbolcularda core alt ekstremite kuvveti antrenmanlarının dinamik denge ve şut isabeti üzerine etkisi. Marmara Üniversitesi Spor Bilimleri Dergisi, 1(1), 51-61. doi.org/10.22396/sbd.2016.5 